\title{
Accuracy of computational welding mechanics methods for estimation of angular distortion and residual stresses
}

\author{
J. Zhu ${ }^{1}(1) \cdot$ M. Khurshid $^{1,2} \cdot$ Z. Barsoum $^{1,3}$
}

Received: 7 June 2018 / Accepted: 8 May 2019 / Published online: 25 May 2019

(C) The Author(s) 2019

\begin{abstract}
This study estimates the angular distortion and residual stresses due to welding using the following methodologies: thermoelastic-plastic, inherent strain (local-global), and substructuring on two types of welded joints (T-type fillet weld and butt weld). The numerical results are compared with the experimental measurements and these methodologies are evaluated in terms of accuracy and computational time. In addition, the influence of welding sequence on distortion and transverse residual stresses has been studied numerically by implementing the thermo-elastic-plastic and inherent strain (local-global) methods on the T-type fillet weld. For the T-type fillet weld, the estimated angular distortion from these methods is much the same and in good agreement with the experimental measurements. For the butt weld, the angular distortion calculated by the inherent strain (local-global) method is largely underestimated. In order to gain a better understanding of where the underestimation of angular distortion in the inherent strain (local-global) method comes from, the study discusses the influence of block length and welding speed on angular distortion. It is found that for long weld length or slow welding speed, activating the plastic strain gradually by dividing the weld bead into an appropriate number of blocks can reduce the level of underestimation of angular distortion.
\end{abstract}

Keywords Angular distortion $\cdot$ Residual stresses $\cdot$ Thermo-elastic-plastic $\cdot$ Inherent strain $\cdot$ Substructuring

\section{Introduction}

Welding is one of the most common joining methods in steel construction. Metal active gas (MAG) together with metal inert gas (MIG) welding processes currently accounts for 70 to $80 \%$ of all manual and robot welding [1]. Additional

Recommended for publication by Commission XIII - Fatigue of Welded Components and Structures

J. Zhu

jinchao@kth.se

M. Khurshid

mansoor.khurshid@bromma.com

Z. Barsoum

zuheir@kth.se

1 KTH Royal Institute of Technology, Teknikringen 08, Stockholm 10044, Sweden

2 Cargotec Sweden AB Bromma Conquip, Kronborgsgränd 23, Kista 16446, Sweden

3 Chalmers University of Technology, Chalmersplatsen 4, Gothenburg 41296, Sweden deformations and residual stresses are produced during welding processes. The welding deformations caused by the shrinkage of filler material can be divided into several types. Transverse shrinkage and angular distortion are caused by shrinkage perpendicular to the weld bead. For a long butt weld, rotational distortion led by this transverse shrinkage may occur. Longitudinal shrinkage, longitudinal distortion, and buckling are due to shrinkage along the weld bead. The welding residual stresses result from the restraints of adjacent base metal during the shrinkage of melted metal.

The welding deformations and residual stresses in a structure may influence the functionality, safety, and durability. Thus, it is of significant importance to reduce adverse deformation and residual stresses. Traditionally, trial and error tests are used to solve these problems. Their drawbacks are that they are timeconsuming and expensive. Nowadays, digital tools involving FE simulations and databases possess of great potential to reduce the lead times of new developments by replacing the physical test loop [2]. One aspect of the digitalised welding process is to use computational welding mechanics (CWM) methods to estimate the mechanical response of welded structures.

A number of computational welding mechanics (CWM) methods have been developed over the last few decades. 
Fig. 1 Schematic illustration of Ttype fillet weld

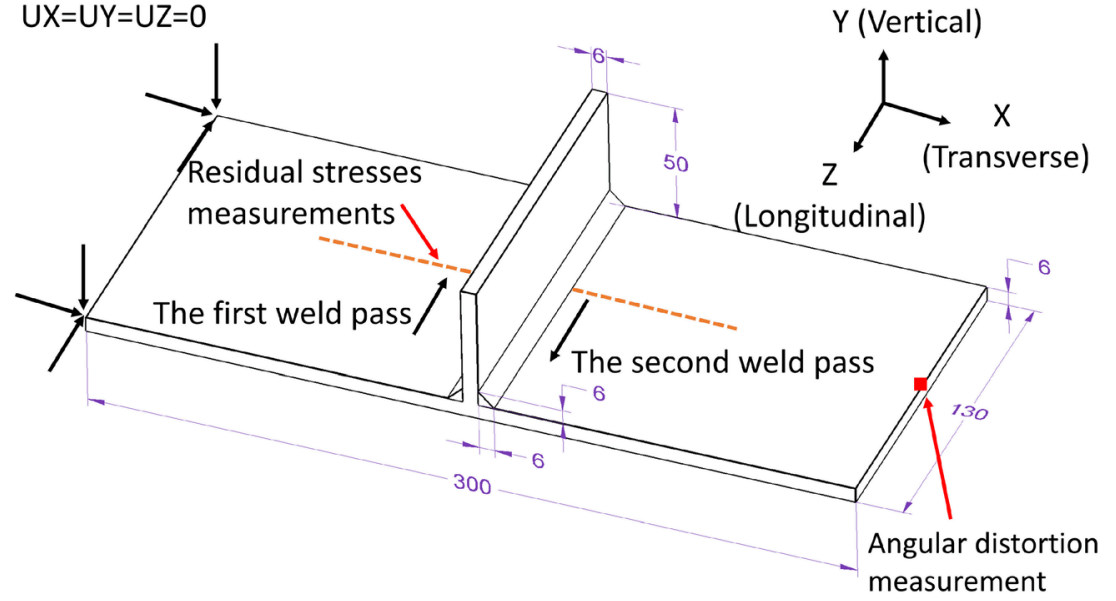

Most studies have been carried out regarding the thermoelastic-plastic method [3-8] which is a coupled thermal and mechanical FE simulation. The thermo-elastic-plastic method has been applied to different types of small welded structures such as butt welds [3], fillet welds [4], and overlap welds [5]. Due to the high level of computational time necessary, some simplified thermo-elastic-plastic approaches have been applied such as block-dumping [6] and substructuring [7, 8]. The substructuring method shows good estimation ability as concerns deformations [8] and residual stresses [7].

In addition to thermo-elastic-plastic method, there is another method entitled the inherent strain method. The concept of inherent strain was developed by Ueda et al. in 1975 [9] and many research work has been carried out based on this concept. In 1983, Ueda et al. [10] utilized inherent strain to measure the residual stresses in long welded joints. From 1989 to 1996, the estimation of residual stresses was developed by using inherent strain in butt welds, T-type fillet welds, and long welds [11-14]. In 1997, Luo et al. [15] applied inherent strain calculated from the thermo-elastic-plastic method where the constraints at each node were defined to calculate welding deformations and residual stresses. Souloumiac et al. [16] came up with the method called the local-global approach to calculating weld deformations where plastic strains calculated from a local 3D model by the thermo-elastic-plastic method were applied as initial strains in the elastic calculation of entire structure. In 2007, Deng et al. [17] developed an elastic finite element method called inherent deformation. In 2012, Khurram et al. [18] investigated an efficient FE technique using equivalent shrinkage force to predict welding deformations and residual stresses in butt joints. Barsoum et al. [19] compared the inherent strain [15], inherent deformation [17], and shrinkage force [18] methods to predict weld distortion of T-type fillet welds and they concluded that the inherent strain method was better than other two methods for angular distortion estimation and inherent deformation and shrinkage force methods are more suitable for estimating longitudinal and transverse shrinkage.

In this study, the following FE simulation methods: thermo-elastic-plastic [3-5], inherent strain (local-global) [16], and substructuring [7, 8] have been implemented both on T-type fillet weld and butt weld specimens to estimate angular distortion and residual stresses. The simulations using these methods have been performed using commercial software: Virfac @ 1.4.3.4 [20]. Through the validation of these methods by the experiments and by comparison, the application of digitalisation in welding can be boosted which leads to the reduction of trial and error tests and saves resources (money, time, material, etc.) accordingly. Moreover, in the inherent strain (local-global) method, several studies [21, 22] contributed to the setup of the size and boundary of the local model. Based on their work, the influence of the block length representing the activation of plastic strain in each time step and welding speed on angular distortion is also discussed.

\section{Computational welding mechanics methods}

\subsection{Inherent strain (local-global)}

The inherent strain (local-global) method needs plastic strains calculated from a local 3D model with thermoelastic-plastic method as input. Afterwards, the elastic FEM analysis of the global model is carried out. Thus, the definition of the local model is very important. The influence of the local boundary condition has been highlighted by Souloumiac [16]. The boundary condition

Table 1 Welding parameters

\begin{tabular}{llll}
\hline Voltage (volts) & Current (amp) & Welding speed $(\mathrm{mm} / \mathrm{s})$ & Heat input $(\mathrm{kj} / \mathrm{mm})$ \\
\hline 30 & 290 & 8.3 & 1.05 \\
\hline
\end{tabular}



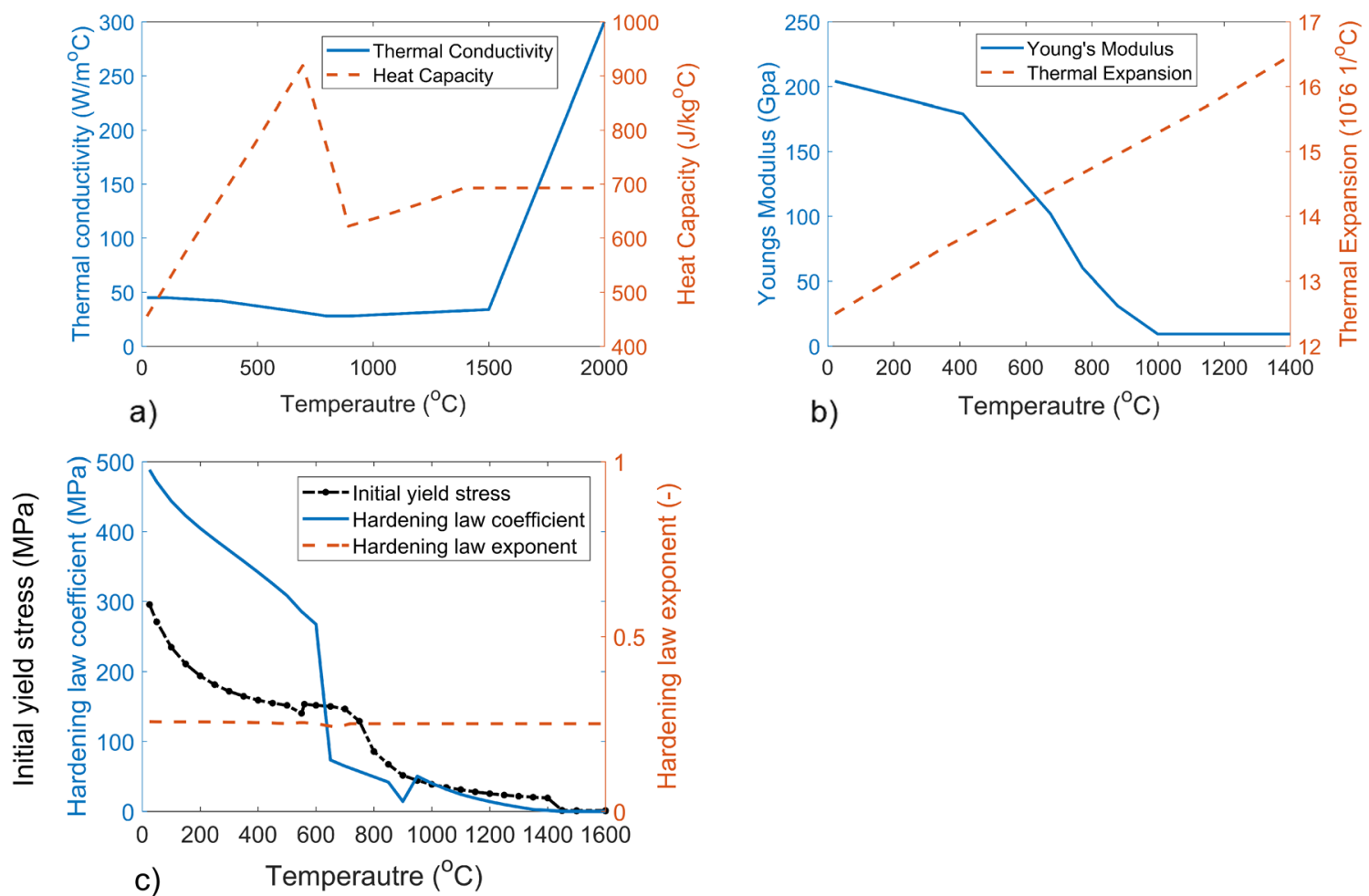

Fig. 2 Temperature-dependent material properties of S355. a Thermal conductivity and heat capacity. b Young's modulus and thermal expansion [23]. c Initial yield stress, hardening law coefficient, and hardening law exponent

of the local model should be close to reality [21]. Duan et al. [22] developed a well-defined method of determining the size and boundary condition of local models. They concluded the local model size should be able to retain the same temperature history as the global model. The
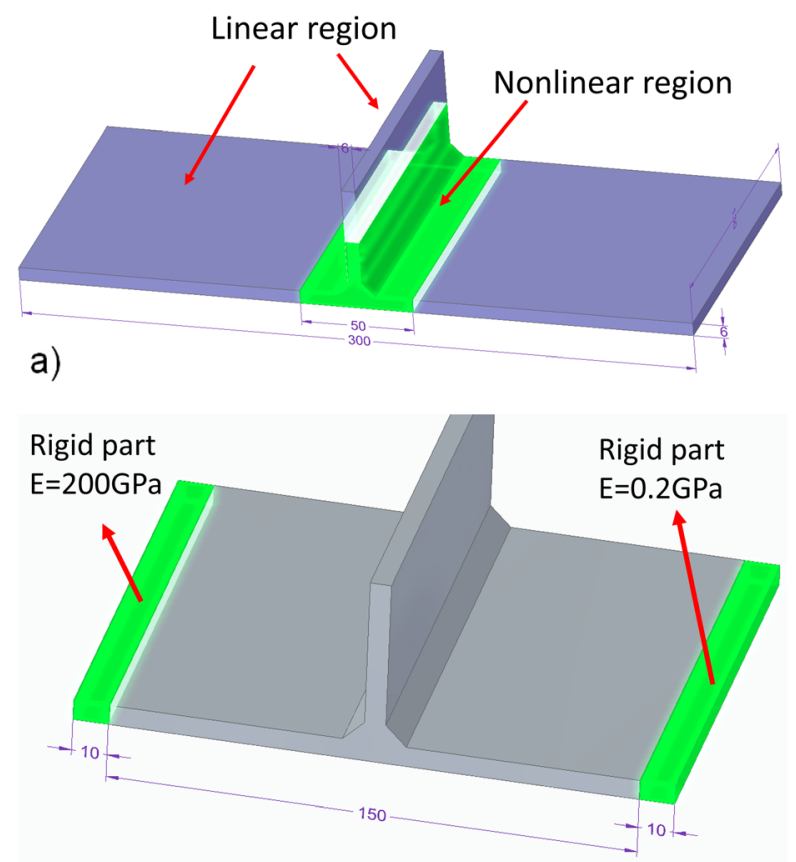

c)

Fig. 3 a Linear and nonlinear regions in substructuring method. b Local model in inherent strain (local-global) method. $\mathbf{c}$ Boundary condition of local model concept of "rigid border" boundary condition was defined by using a rigid part added to the frontier of the local model to keep the boundary in plane. In order to represent the mechanical conditions imposed by the rest of the structure, the rigidity of the rigid part may be changed by adjusting b)

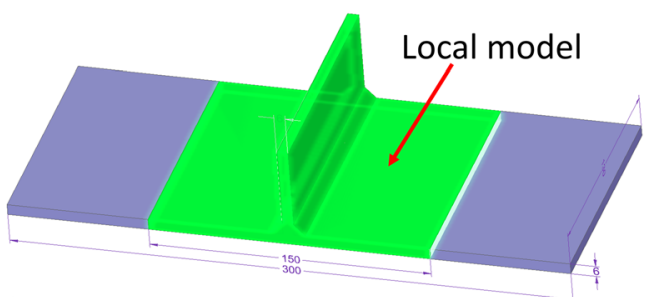


Table 2 Elastic isotropic material model

Density $\left(\mathrm{kg} / \mathrm{m}^{3}\right)$

7840

Young's modulus (GPa)

200

Poisson's ratio

0.29

Thermal expansion coefficient

0.0000125

Thermal conductivity $\left(\mathrm{W} /\left(\mathrm{m}{ }^{\circ} \mathrm{C}\right)\right.$

45

Specific heat capacity $\left(\mathrm{J} /\left(\mathrm{kg}{ }^{\circ} \mathrm{C}\right)\right.$

the value of Young's modulus. In this study, the local model size and local boundary condition are defined according to Duan's work [22].

\subsection{Substructuring}

The simulation model using the substructuring technique is performed by dividing the entire structure into two parts: the linear region and the nonlinear region. The elastic isotropic material model is assigned to the linear region with almost elastic behavior during the welding process. The elasticplastic material model, assuming isotropic hardening, is applied to the nonlinear region which is close to the heat source.

\section{T-type fillet welds}

\subsection{Experiments}

Bhatti et al. [23] carried out comprehensive simulation work on angular distortion and residual stresses in T-type fillet welds in S355, S700, and S960 steels. In this study, the welding parameters, experimental setups, part of material model, and experimental measurements described in [23] are applied. Figure 1 shows a schematic illustration of the geometry of the specimen, the experimental setup, and the measuring locations. The welding parameters are listed in Table 1.

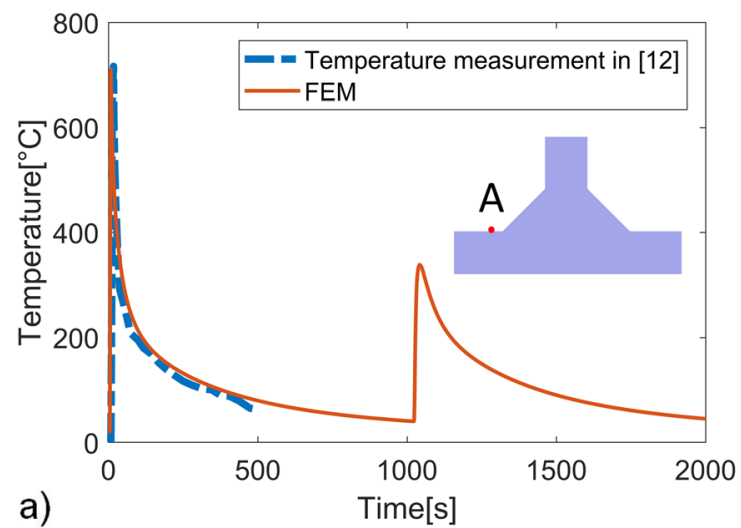

Fig. 4 Temperature histories. a Point A. b Point B

\subsection{Finite element model}

\subsubsection{Material modeling}

The base plate and filler material are assumed to have the same material properties in the following numerical simulation methods: the thermo-elastic-plastic on the global model, the local model in inherent strain (local-global) method, and the nonlinear region in substructuring method. A J2-type isotropic hardening law [24] without considering phase transformation has been applied to the base plate and filler material. The relationship between the stress and strain of the material is shown in Eq. (1).

$\sigma=\sigma_{y}+H\left(\varepsilon^{p}\right)^{N}$

where $\sigma$ is the total stress, $\sigma_{y}$ is the initial yield stress, $H$ is the hardening law coefficient, $\varepsilon^{p}$ is the plastic strain, and $N$ is the hardening law exponent.

JMat Pro® [25] has been used to simulate the flow stress of the material. The input chemical composition is based on typical values provided by Swedish Steel AB (SSAB). The temperature-dependent initial yield stress, hardening law coefficient, and hardening law exponent are calculated from the flow stress under the strain rate of $0.1 \mathrm{~s}^{-1}$ by using Eq. (1) (see Fig. 2c). The temperature-dependent thermal expansion, thermal conductivity, heat capacity, and Young's modulus for S355 below $1500^{\circ} \mathrm{C}$ are from [23], as seen in Fig. 2a and b. Artificial thermal conductivity has been induced to consider the heat transfer in the melting weld pool, which is assumed to be $300 \mathrm{~W} /\left(\mathrm{m}^{\circ} \mathrm{C}\right)$ at $2000{ }^{\circ} \mathrm{C}$ [26]. Density and Poisson ratio are independent of temperature with the value of $7840 \mathrm{~kg} / \mathrm{m}^{3}$ and 0.29 respectively [23].

The elastic isotropic material model is assigned to the linear region in the substructuring method (see Fig. 3a) and global model in the inherent strain (local-global) method. The parameters of the elastic isotropic material model are listed in Table 2.

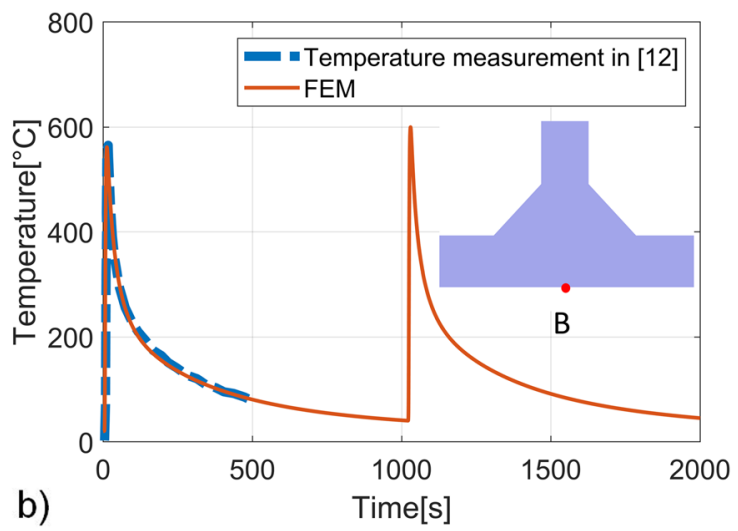



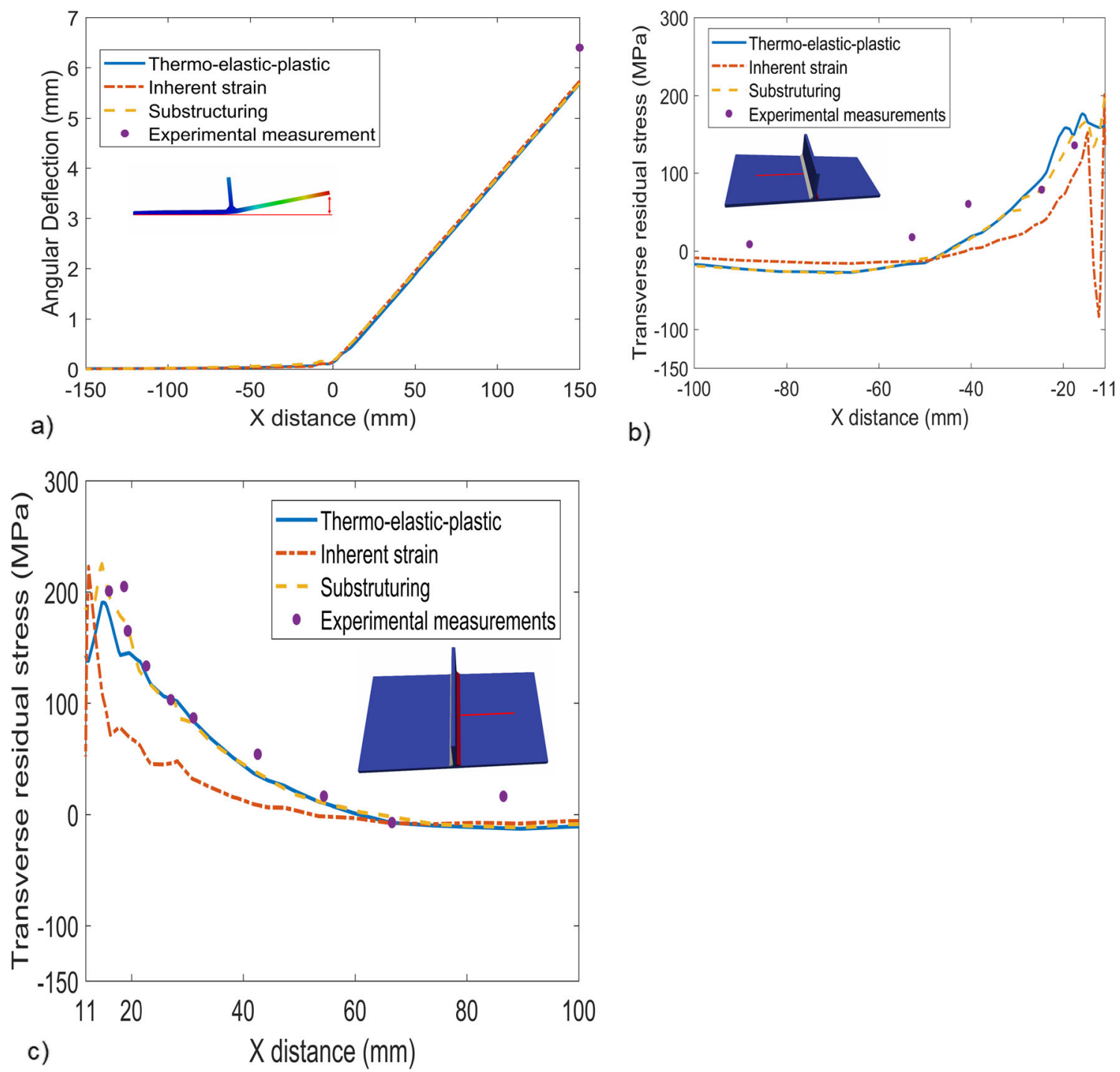

Fig. 5 Estimation of angular distortion and residual stresses using thermo-elastic-plastic, inherent strain (local-global), and substructuring methods. a Angular distortion. b Transverse residual stresses on the left side. $\mathbf{c}$ Transverse residual stresses on the right side

\subsubsection{Heat source modeling}

The heat source has been modeled as a cylindrical shape applying a constant heat density to the weld bead. The radial dimensions of the heat source in front, behind, and to the side are equal to the radius 恶. The energy of heat source Q (Joule/ s) is expressed in Eq. (2)

$Q=\eta_{\operatorname{arc}} \cdot U \cdot I$

where $\eta_{\text {arc }}$ is the arc efficiency, $U$ is the voltage, and I is the current.

The radius of heat source and arc efficiency have been tuned according to the temperature histories at the points $\mathrm{A}$ and $\mathrm{B}$ described in [23]. The convection is set to $20 \mathrm{~W} / \mathrm{m}^{2}{ }^{\circ} \mathrm{C}$ corresponding to a still air environment. The temperature histories from the case where arc efficiency is $85 \%$ and the radius of cylindrical shape heat source is $4.24 \mathrm{~mm}$ shows good agreement (see Fig. 4a and b).

\subsubsection{Boundary condition and mesh}

In this study, the size of the local model can be seen in Fig. 3b which has the same temperature history curve as those in Fig. 4. In order to maintain the rigidity of the rigid part close to reality, the value of Young's modulus applied to the rigid part is studied. Young's modulus of the rigid part on the fixture side is set to $200 \mathrm{GPa}$ to represent the effect of rigid clamping. Young's modulus of the rigid part on the free edge of the base plate is set to $0.2 \mathrm{GPa}$ to represent the constraints from the rest of the structure.

In order to achieve mesh independent results, mesh independency was also studied. The angular distortion was 


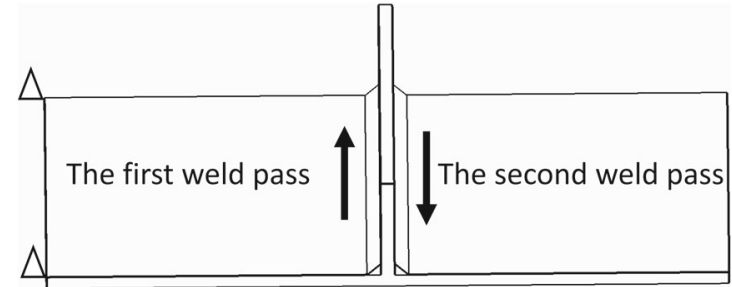

a) Welding sequence 1

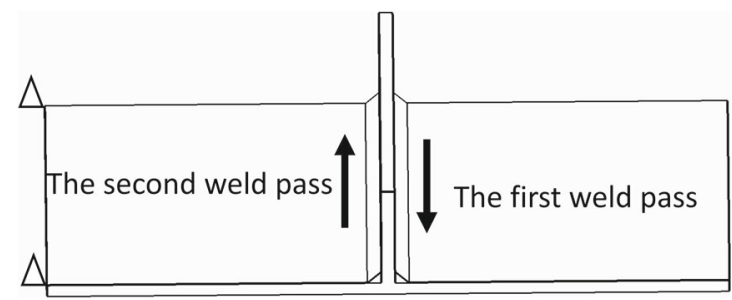

c) Welding sequence 3

Fig. 6 Welding sequence scenarios: $\mathbf{a}, \mathbf{b}, \mathbf{c}, \mathbf{d}$

compared under three different meshes with element sizes 0.5 , 1 , and $2 \mathrm{~mm}$, respectively. Under mesh size 0.5 and $1 \mathrm{~mm}$, no obvious difference in angular distortion was observed. Thus, the minimum element length is defined as $1 \mathrm{~mm}$. The fine mesh is applied in and around welds and the coarse mesh on the rest of the part. The total number of elements is 160,000 .

\subsection{Comparison}

The estimated angular deflections using thermo-elastic-plastic, inherent strain (local-global), and substructuring methods are almost the same (see Fig. 5a). These methods underestimate the angular deflection by around $11 \%$ compared with the experimental measurement. Figure $5 \mathrm{~b}$ and c show the comparison of experimental and estimated transverse residual stresses in front of the weld toe. The location of the measuring

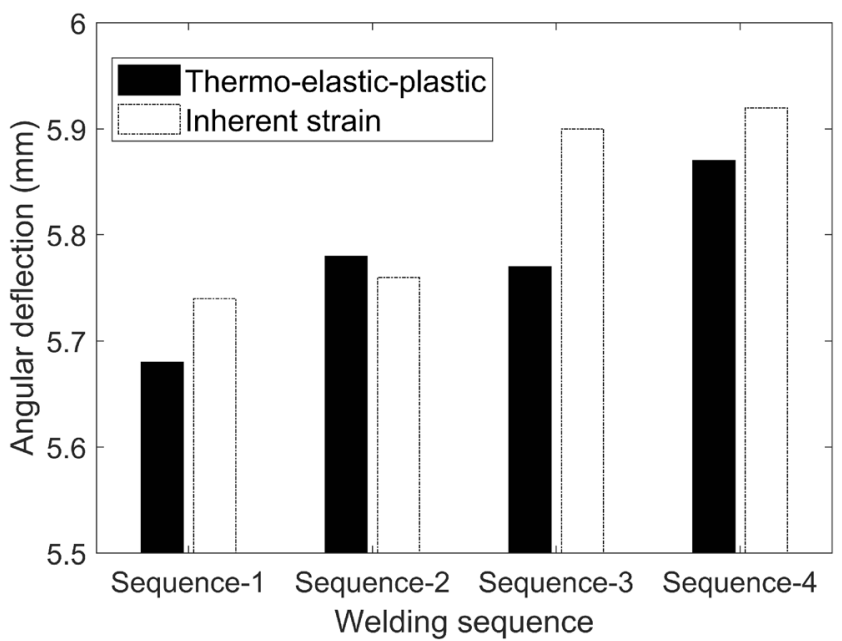

Fig. 7 Comparison of angular distortion with different welding sequence by Themo-elastic-plastic and Inherent strain (local-global) method

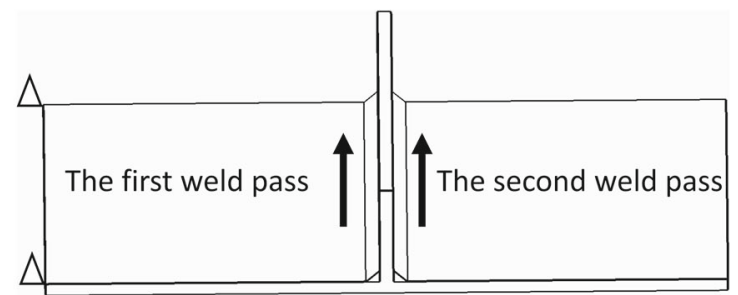

b) Welding sequence 2

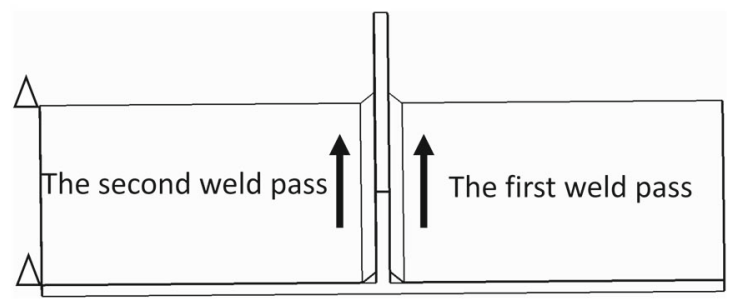

d) Welding sequence 4

points is marked with red lines. The magnitude of tensile residual stresses calculated from the inherent strain (localglobal) method is less than that of the thermo-elastic-plastic and substructuring methods and the stresses measured. Regarding computational time, using the inherent strain (local-global) method only takes a few minutes which does not include the time for thermo-elastic-plastic calculation on the local model. The computational time varies with the size of the local model. It took $4 \mathrm{~h}$ in this case. The computational time used was $8.5 \mathrm{~h}$ for the thermo-elastic-plastic method and $8 \mathrm{~h}$ for the substructuring method.

\subsection{Influence of welding sequence}

In order to study the influence of the welding sequence on distortion and residual stresses, four different welding sequence scenarios were selected in which the thermo-elasticplastic and inherent strain (local-global) methods were applied (see Fig. 6). In the inherent strain (local-global) method, the plastic strains are from the thermo-elastic-plastic calculation on local models where the welding direction of passes are the same as those in the global model.

It is observed that for sequences 1 and 2, the difference between angular deflections estimated by the thermo-elasticplastic method is $0.1 \mathrm{~mm}$ in Fig. 7. The same difference can be found between sequences 3 and 4 . These results indicate that for T-type fillet welds, applying opposite welding directions for two passes results in less angular deflection than in the same welding direction. However, no difference can be seen between the deflections estimated by the inherent strain method (local-global) using different welding directions.

As can be seen in Fig. 7, the deflections estimated by the thermo-elastic-plastic method in sequences 1 and 2 are $0.09 \mathrm{~mm}$ smaller than those in sequences 3 and 4 . 

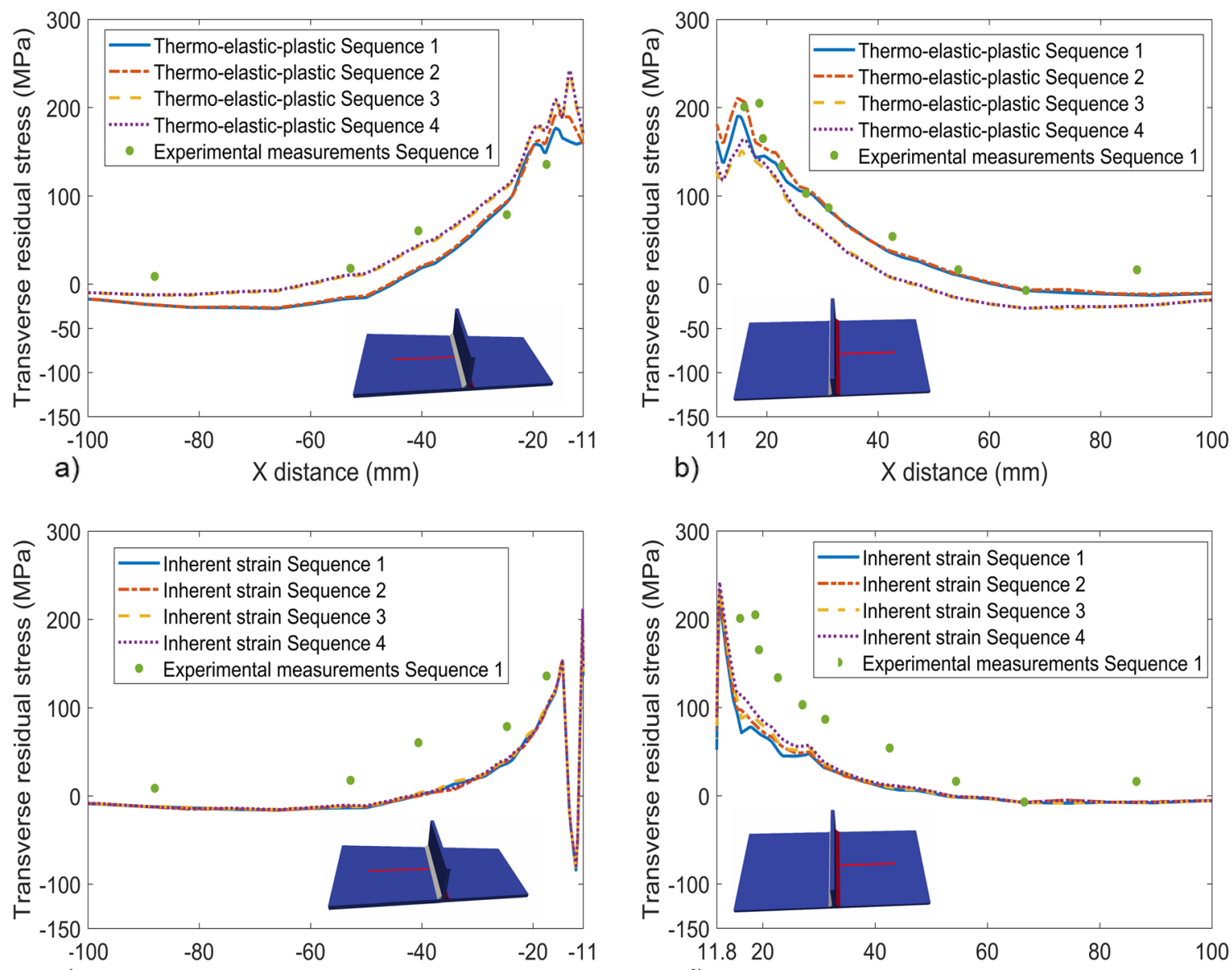

C) $\quad X$ distance $(\mathrm{mm})$

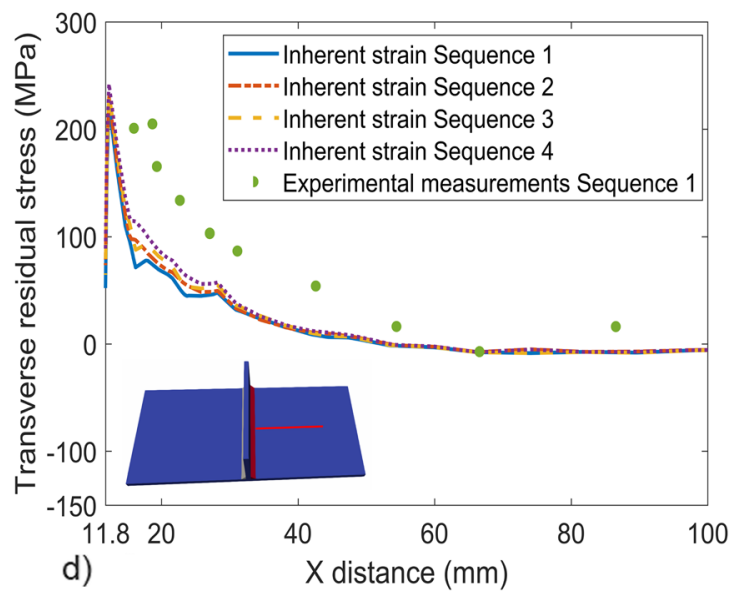

Fig. 8 Comparison of transverse residual stresses with different welding sequence: on the left (a, c) and right side (b, d) computed by Thermo-elasticplastic $(\mathrm{a}, \mathrm{b})$ and Inherent strain (global-local) method (c, d)

Consequently, the case where the first weld pass is close to the rigid clamping boundary causes less deflection than the case where the first weld pass is close to the free edge. A greater difference $(0.16 \mathrm{~mm})$ can be found between the estimated deflections in these cases using the inherent strain (localglobal) method compared with the thermo-elastic-plastic method. The inherent strain (local-global) method is able to estimate the difference of angular distortion caused by change of weld position with good accuracy.
In Fig. $8 \mathrm{a}$ and $\mathrm{b}$, it can be seen that both estimated transverse residual stresses on the left side in sequences 1 and 2 are lower than those in sequences 3 and 4 . The opposite situation can be observed on the right side. This proves that the position of weld pass does influence transverse residual stresses. The transverse residual stresses on the first weld pass side are lower than those on the second weld pass side. Any difference between the transverse residual stresses during different welding sequences estimated by the inherent strain (local-global) are not obvious.
Fig. 9 Schematic illustration of butt weld specimen

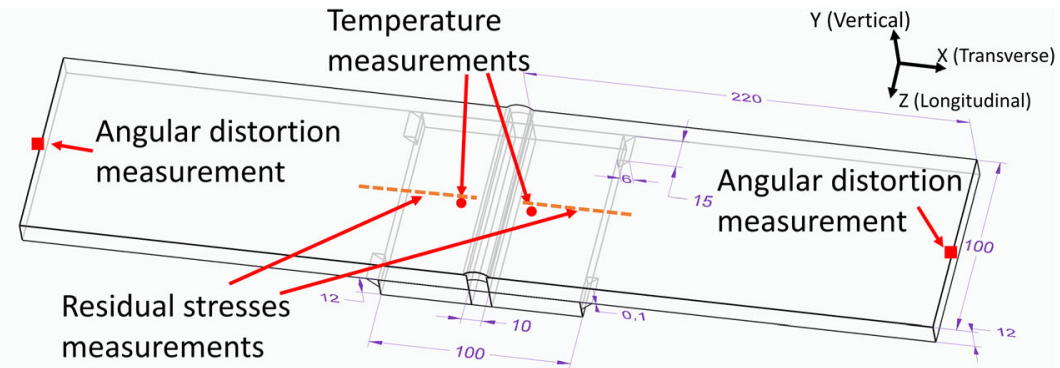


Table 3 Welding parameters of butt weld

\begin{tabular}{lllll}
\hline & Voltage (volts) & Current (amp) & Welding speed (mm/s) & Heat input (kj/mm) \\
\hline Welding pass 1 & 21.3 & 189 & 1.38 & 2.9 \\
Welding pass 2 & 21.3 & 200 & 2.22 & 1.9
\end{tabular}

\section{Butt welds}

\subsection{Experiments}

\subsubsection{Welding process}

The butt weld specimen consisted of one backing plate (S355J2) and two base plates (S600MC) which were tack welded with a joint gap of $10 \mathrm{~mm}$ (see Fig. 9. The butt weld was produced manually using metal active gas (MAG) with the multi-pass process ( 2 passes). The welding parameters can be seen in Table 3. Three identical samples were manufactured. The deflection measurements from these samples were averaged.

\subsubsection{Temperature measurements}

During the experiment, temperature data was collected using K-type thermocouples. Two holes with a diameter of $3 \mathrm{~mm}$ and a depth of $2 \mathrm{~mm}$ were drilled to insert the thermocouples
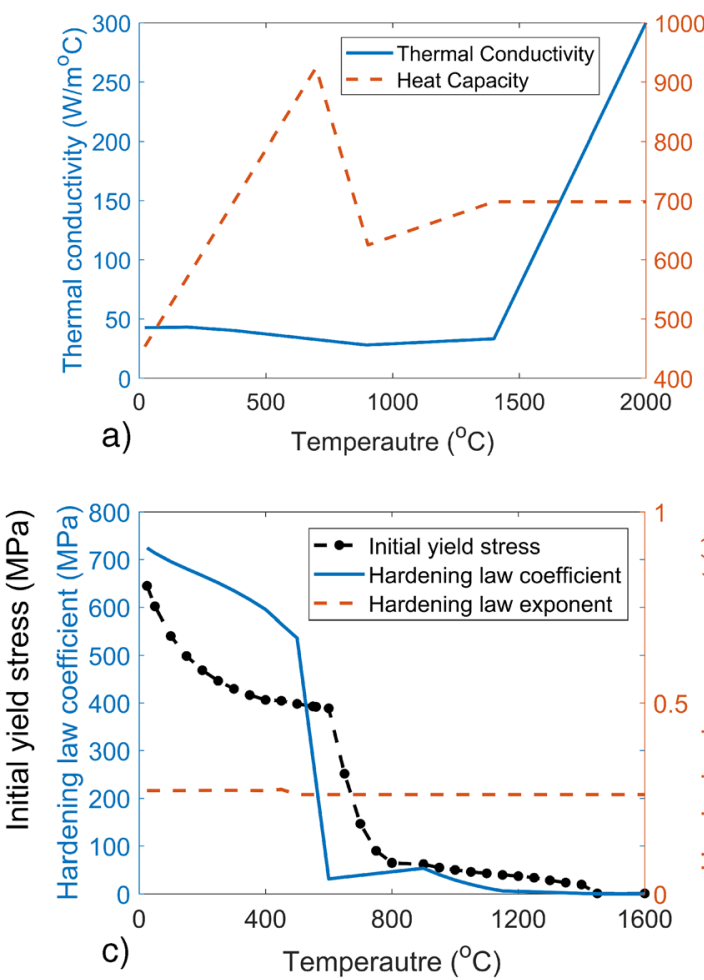

Fig. 10 Temperature-dependent material properties of S600MC and filler material. a Thermal conductivity and heat capacity. b Young's modulus and thermal expansion [23]. c Initial yield stress, hardening law which are $15 \mathrm{~mm}$ from the middle of weld bead, as shown in Fig. 9.

\subsubsection{Residual stresses measurements}

The residual stresses were measured using the X-ray diffraction method with $\mathrm{Cr} \mathrm{K} \alpha$ radiation. Measurement line is approximately $14 \mathrm{~mm}$ away from the center line of the specimen, because of the drilled holes in the center line of the samples (see Fig. 9). The locations are $\pm 58 \mathrm{~mm}, \pm 38 \mathrm{~mm}, \pm 23 \mathrm{~mm}, \pm$ $14 \mathrm{~mm}, \pm 12 \mathrm{~mm}, \pm 10 \mathrm{~mm}$, and $\pm 8.5 \mathrm{~mm}$, where zero position is the middle of the weld bead. The estimated penetration depth is $5 \mu \mathrm{m}$ and the collimator size is $1 \mathrm{~mm}$.

\subsection{Finite element model}

\subsubsection{Material modeling}

The base plates (S600MC) and filler material are modeled using J2-type isotropic hardening law with flow stress
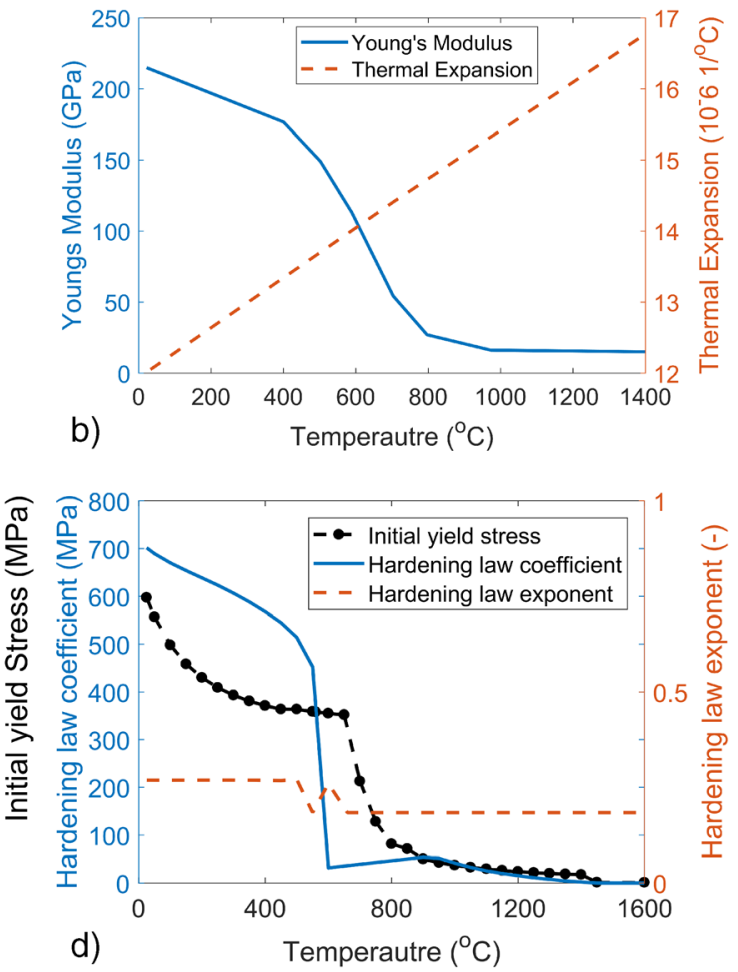

coefficient, and hardening law exponent of S600MC. d Initial yield stress, hardening law coefficient, and hardening law exponent of filler material 
Table 4 Chemical composition for S600MC and filler material (\% weight)

\begin{tabular}{|c|c|c|c|c|c|c|c|c|c|c|}
\hline & $\mathrm{C}(\%)$ & $\mathrm{Si}(\%)$ & $\operatorname{Mn}(\%)$ & $\mathrm{P}(\%)$ & $\mathrm{S}(\%)$ & Mo (\%) & $\mathrm{V}(\%)$ & $\mathrm{Nb}(\%)$ & $\mathrm{Ti}(\%)$ & $\mathrm{Al}(\%)$ \\
\hline $\begin{array}{l}\text { S600MC } \\
\text { EN 10149-2 standard }\end{array}$ & Max 0.12 & Max 0.5 & Max 1.9 & Max 0.025 & Max 0.015 & Max 0.5 & Max 0.2 & Max 0.09 & Max 0.22 & Min 00.015 \\
\hline $\begin{array}{l}\text { Filler material } \\
\text { ASME SFA-5.20: E71T-12C-JH8 }\end{array}$ & Max 0.12 & Max 0.9 & Max 1.75 & Max 0.03 & Max 0.03 & & & & & \\
\hline
\end{tabular}

calculated from JMat Pro® (see Fig. 10c and d). Table 4 presents the typical chemical composition for base plates and filler material according to EN 10149-2 Standard and ASME SFA-5.20: E71T-12C-JH8. The other thermal and mechanical material properties of base plates and filler material are assumed to be the same as the material model of S700 from [23] without considering phase transformation (see Fig. 10a and b). The annealing temperature is set to be $1300{ }^{\circ} \mathrm{C}$ [27] to represent the effect of multi-pass weld. The material model of the backing plate is the same as the defined material model for $\mathrm{S} 355$. The elastic isotropic material model for base plates (S600MC) and filler material can be seen in Table 5. The material models are assigned to the different parts in Fig. 11, according to the description in the previous Section 3.2.1.

\subsubsection{Heat source modeling}

A cylindrical shape with a 5-mm radius and 10-mm height has been modeled as the heat source for the first weld pass. The power density distribution is constant in the volume of the cylindrical heat source. For the second weld pass, the same heat source as in Section 3.2.2 is applied and the radius 퓻 is set to $6.5 \mathrm{~mm}$. The heat source efficiency is assumed to be 0.8 and the effective power for the first and second pass is $3388 \mathrm{~W}$ and $3509 \mathrm{~W}$ respectively using Eq. (2). The isothermal contour plots for the fusion zone, HAZ, and penetration profile show a good match with the macrographs for both weld passes (see Fig. 12a and b). In order to consider the heat sink effect on the bottom surface of the backing plate, a heat convection coefficient of $300 \mathrm{~W} /\left(\mathrm{m}^{2}{ }^{\circ} \mathrm{C}\right)$ was applied to the entire bottom surface of the backing plate [28]. Convection was set at a constant value of $20 \mathrm{~W} / \mathrm{m}^{2}{ }^{\circ} \mathrm{C}$ corresponding to a still air environment on all surfaces except the bottom surface of the

Table 5 Elastic isotropic material model

\begin{tabular}{lc}
\hline Density $\left(\mathrm{kg} / \mathrm{m}^{3}\right)$ & 7840 \\
Young's modulus (Gpa) & 215 \\
Poisson's ratios & 0.29 \\
Thermal expansion coefficient & 0.00001205 \\
Thermal conductivity $\left(\mathrm{W} /\left(\mathrm{m}^{\circ} \mathrm{C}\right)\right.$ & 42.5 \\
Specific heat capacity $\left(\mathrm{J} /\left(\mathrm{kg}^{\circ} \mathrm{C}\right)\right.$ & 453 \\
\hline
\end{tabular}

backing plate. The initial temperature was set at $34^{\circ} \mathrm{C}$ according to the measurements.

The temperature histories from FEM simulation show good agreement with the measurements at $15 \mathrm{~mm}$ from the weld centre line (see Fig. 12c). The peak temperatures from FEM simulation for both passes are slightly lower than those measured.

\subsubsection{Boundary condition and mesh}

No external constraint was applied to the butt weld specimen during the manufacturing process. For the global model in the thermo-elastic-plastic, inherent strain (local-global), and substructuring methods, the rigid body motion was prevented. For the thermo-elastic-plastic simulation on the local model in the inherent strain (local-global) method, two rigid parts with Young's modulus of $0.2 \mathrm{GPa}$ were applied to both sides of the local model to represent the constraint effect from the rest of the structure (see Fig. 8c).

The length of elements in the weld beads were set at $1.5 \mathrm{~mm}$ for both passes. The coarse mesh was applied to the linear region. The total number of elements was 151,542.

\subsection{Comparison}

The estimated angular deflection from the thermo-elastic-plastic, inherent strain (local-global), and substructuring methods is $3.7 \mathrm{~mm},-2.6 \mathrm{~mm}$, and $-4.7 \mathrm{~mm}$ respectively (see Fig. 13a). In comparison to the experimental measurement $(-3.5 \mathrm{~mm})$, the thermo-elastic-plastic method shows good agreement. The inherent strain (local-global) method underestimates the angular deflection by $26 \%$ and the substructuring method overestimates the angular deflection by $34 \%$.

For transverse residual stresses, the trend is captured and relatively large differences can be observed between the estimated stresses from the thermo-elastic-plastic, inherent strain, and substructuring methods and the experimental measurements. In order to increase accuracy, phase transformation could be included in further studies.

The estimated longitudinal residual stresses from the thermo-elastic-plastic, inherent strain, and substructuring methods show good agreement with the measurements, as shown in Fig. 13d and e. 


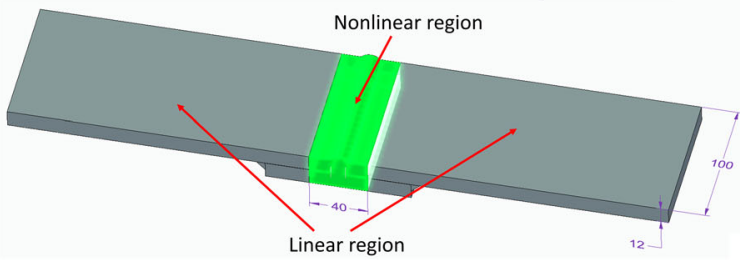

a)

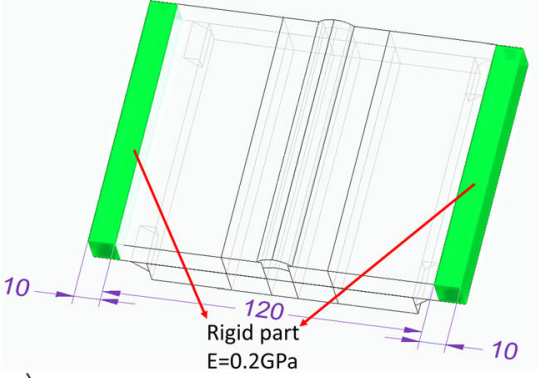

c)

Fig. 11 a Linear and nonlinear regions in substructuring method. b Local model in Inherent strain (local-global) method. $\mathbf{c}$ Boundary condition of local model

The computational time for the thermo-elastic-plastic, inherent strain (local-global), and substructuring methods are $18,0.2$, and $12 \mathrm{~h}$ respectively. The computational time for the thermo-elastic-plastic analysis on the local model is $10 \mathrm{~h}$. The computational time for the substructuring method is $30 \%$ less than the thermo-elastic-plastic method.

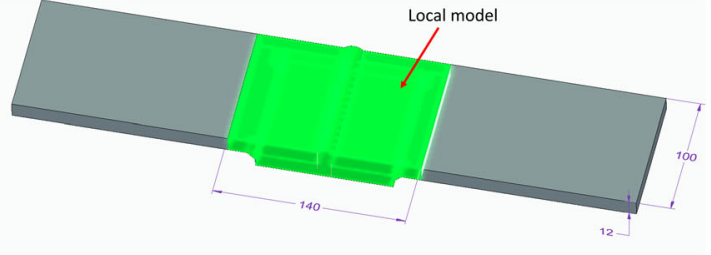

b)

\section{Discussion}

Although the inherent strain (local-global) method needs very little computational time, a certain level of underestimation can be observed between the estimated and measured angular deflection and residual stresses (see Figs. 5 and 10). This type of difference could be observed in [22] as well. In order to
Fig. 12 Heat source calibration. a Macrograph and isotherms for the first deposited pass. $\mathbf{b}$

Macrograph and isotherms for the second deposited pass. $\mathbf{c}$

Temperature histories at $15 \mathrm{~mm}$ from the weld center line

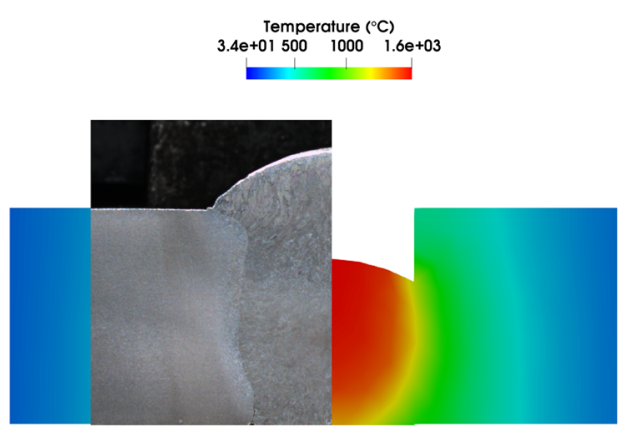

a)

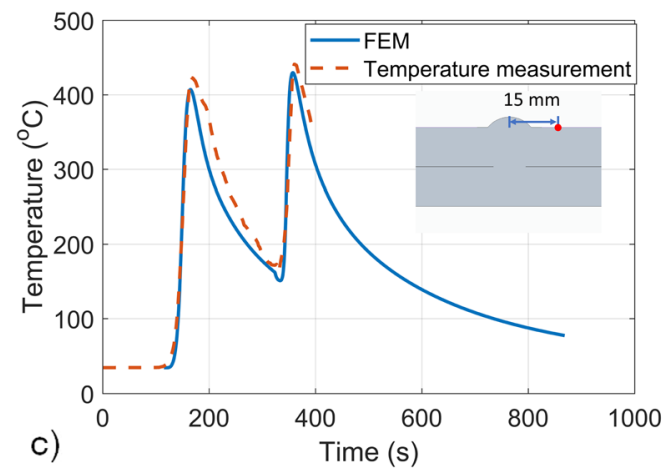

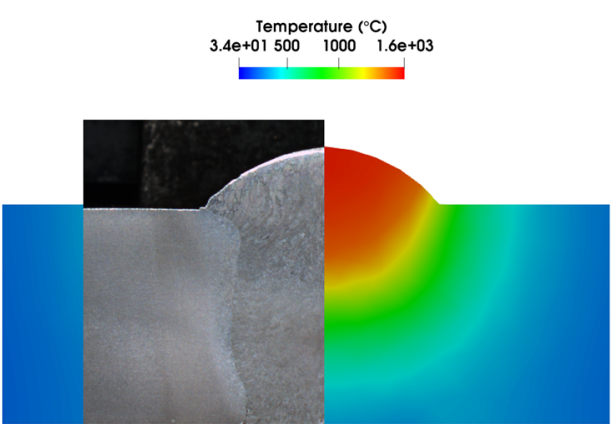

b) 

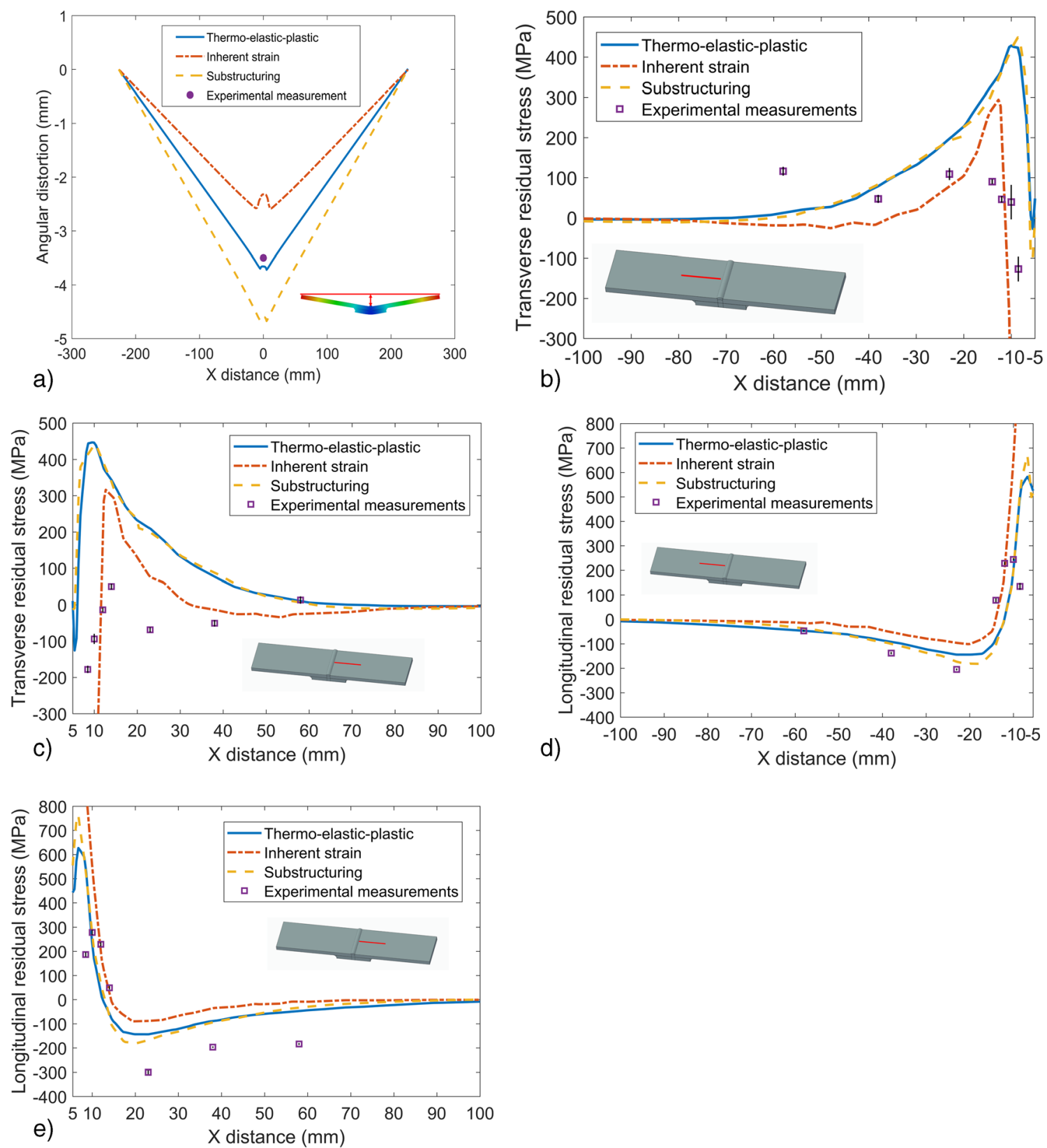

Fig. 13 Estimation of angular distortion and residual stresses using thermo-elastic-plastic, inherent strain (local-global), and substructuring methods. a Angular distortion. b Transverse residual stresses on the left

side. c Transverse residual stresses on the right side. d Longitudinal residual stresses on the left side. e Longitudinal residual stresses on the right side

As can be seen in Fig. 14, in both the T-type fillet weld and understand where this variation comes from, the influence of block length and welding speed on angular distortion will be discussed.

\subsection{Influence of block length}

In the inherent strain (local-global) method, the activation of plastic strain in the weld bead can be achieved in a single time step or divided into several time steps. The block length represents the method of activating the plastic strain. butt weld specimens, reducing the block length results in the increase of angular deflection. It is due to the reason that the activation of weld bead also provides the additional stiffness of the structure. For the T-type fillet weld specimen, the angular deflection increases by $2 \mathrm{~mm}$ when the block length changes from 130 to $16.25 \mathrm{~mm}$. The level of accuracy is defined by the ratio of estimated and measured angular deflection. As can be seen, the inherent strain (local-global) method underestimates the angular deflection by about $17 \%$ with a block length 

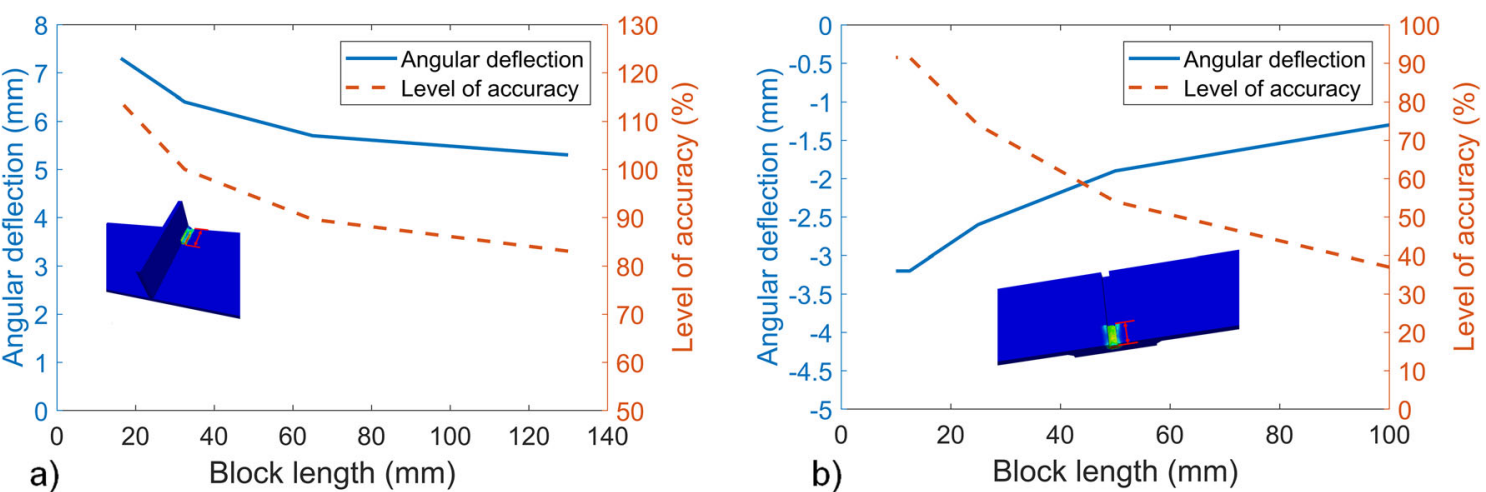

Fig. 14 Influence of the block length. a T-type fillet weld specimen. b Butt weld specimen

of $130 \mathrm{~mm}$ and overestimates the angular deflection by around $14 \%$ with a block length of $16.25 \mathrm{~mm}$. For the butt weld specimen, reducing the block length results in increasing the level of accuracy significantly which is from 37 to $91 \%$.

\subsection{Influence of welding speed}

There is a difference between the welding speed of the T-type fillet weld $(8.3 \mathrm{~mm} / \mathrm{s})$ and butt weld $(1.38 \mathrm{~mm} / \mathrm{s}$ for the first pass and $2.22 \mathrm{~mm} / \mathrm{s}$ for the second pass). In order to include the influence of welding speed, a new parameter $t_{b}$ "block period" calculated by Eq. 3 is induced.

$t_{b}=\frac{l_{b}}{v}$

where $t_{b}$ is the block period, $l_{b}$ is the length of block, and $v$ is the welding speed.

In Fig. 15a, the level of accuracy is increased with the decrease of the block period and the curve trends for the Ttype fillet weld and butt weld are similar. The overlap part of

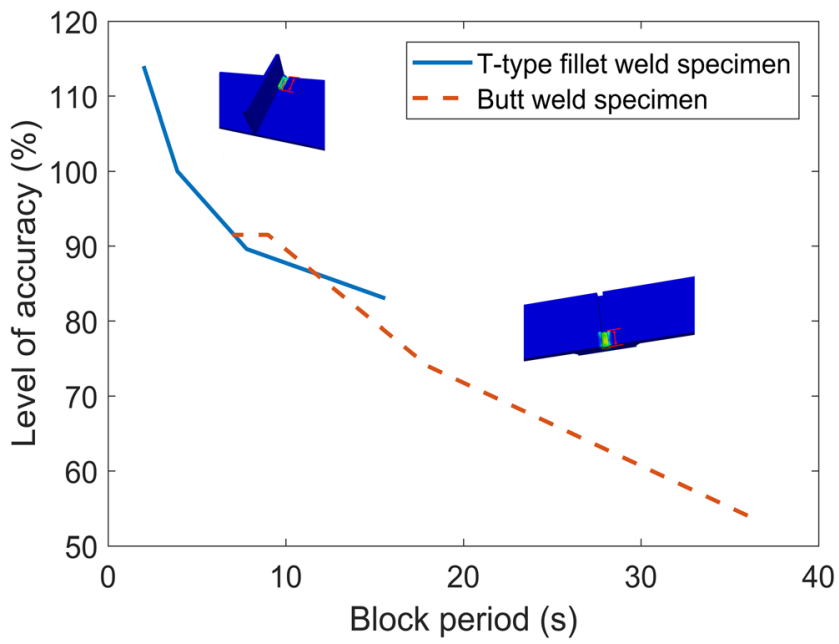

Fig. 15 Influence of block period this line between block period 7 and $16 \mathrm{~s}$ indicates that the level of accuracy is independent of the type of weld. In addition, erroneous results could be observed when very short block period is applied as the plastic strain is extracted when the structure cools down to room temperature. It is suggested that an appropriate block period be taken into account in the inherent strain (local-global) method.

In the inherent strain (local-global) method in Section 3 and 4 , the weld bead has been divided into two blocks for T-type fillet weld and four blocks for butt weld (see Fig. 16a and b). The level of accuracy is increased by $6 \%$ for T-type fillet weld specimen and $37 \%$ for butt weld specimen compared with the case where the plastic strain is activated in a single time step. Consequently, dividing the weld bead into an appropriate number of blocks and activating the plastic strain gradually can reduce the level of underestimation on angular distortion when using inherent strain (local-global) method.

The cooling time $\Delta t_{8 / 5}$ between 800 and $500{ }^{\circ} \mathrm{C}$ for the $\mathrm{T}$ type fillet weld specimen is $5.6 \mathrm{~s}$ and for the butt weld specimen is about $15 \mathrm{~s}$, according to Eq. 4 [29].

$\Delta t_{8 / 5}=\left(6700-5 \cdot T_{0}\right) \cdot \bar{q}_{w} \cdot\left(\frac{1}{500-T_{0}}-\frac{1}{800-T_{0}}\right)$

where $\Delta t_{8 / 5}$ is the cooling time between 800 and $500^{\circ} \mathrm{C}, T_{0}$ is the preheating temperature ${ }^{\circ} \mathrm{C}$, and $\bar{q}_{w}$ is the gross heat input per unit length of weld $\mathrm{kJ} / \mathrm{mm}$.

It is found that the cooling time $\Delta t_{8 / 5}$ for the butt weld is much higher than the one for the T-type fillet and values are similar to the block period applied to those two specimens. The cooling time $\Delta t_{8 / 5}$ is dependent on many factors such as heat input, plate thickness, joint type, and welding process [30] and could be utilized as a reference for the block period. In order to determine the appropriate block period in the inherent strain (local-global) method, the relationship between the stains in the weld and temperature history could be included in further studies. 


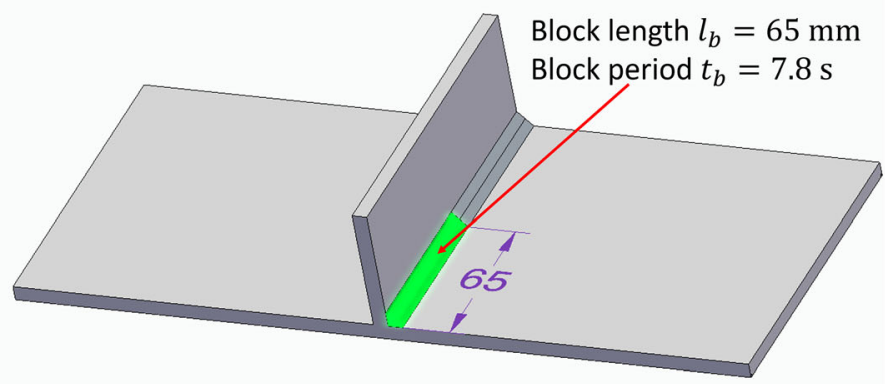

a)

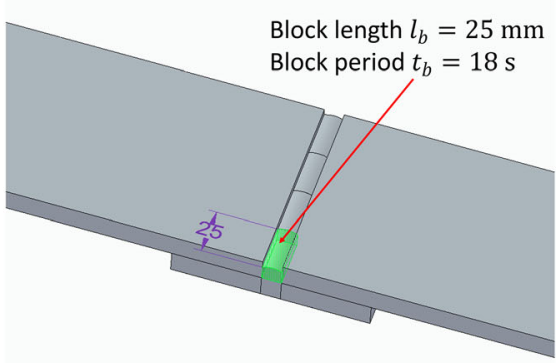

b)

Fig. 16 Illustration of the block length and block period. a T-type fillet weld specimen. b Butt weld specimen

\subsection{Computational time and accuracy}

As shown in Fig. 17, the accuracy and computational time of the thermo-elastic-plastic method are greater than the inherent strain (local-global) and substructuring methods. The substructuring method reduces computational time by 6 to $30 \%$ compared to the thermo-elastic-plastic method and has good accuracy of estimation. The inherent strain (localglobal) method is very time-efficient when having plastic strains as input. Computational time of the thermo-elasticplastic analysis on the local model is $4 \mathrm{~h}$ for the T-type fillet weld and $10 \mathrm{~h}$ for the butt weld, whereas the accuracy of the inherent strain (local-global) method is lower than the thermo-elastic-plastic and substructuring methods. In the case of applying the same plastic strains to the T-type fillet weld, the accuracy of estimated angular distortion is varied from 83 to $114 \%$. The variation in the butt weld specimen is even greater ranging from 37 to $91.5 \%$. The dotted line represents the variation of accuracy of estimated angular distortion. The reasons for these variations have been discussed in Sections 5.1 and 5.2.

\section{Conclusions}

This study conducted the estimation of angular distortion and residual stresses on T-type fillet weld and butt weld specimens by applying the thermo-elastic-plastic, inherent strain (localglobal), and substructuring methods. These methods are compared in terms of accuracy and computational time. The influence of the welding sequence on distortion and transverse residual stresses was studied numerically by implementing the thermo-elastic-plastic and inherent strain (local-global) methods on T-type fillet welds. Moreover, in order to achieve a better understanding of the variations in the inherent strain (local-global) method, the influence of block length and welding speed on angular distortion has been discussed. Conclusions are as follows:

- The estimated angular distortion and residual stresses in front of the weld toe from the thermo-elastic-plastic, inherent strain (local-global), and substructuring methods are in good agreement with the experimental measurements of T-type fillet welds.

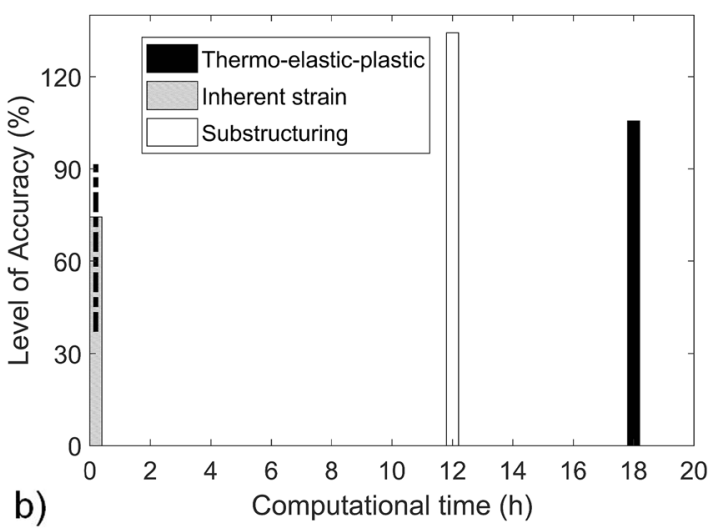

Fig. 17 Computational time and accuracy of the thermo-elastic-plastic, inherent strain, and substructuring methods. a T-type fillet weld specimen. b Butt weld specimen 
- Substructuring method can reduce computational hours by up to $30 \%$ as compared to the thermo-elastic-plastic method. The inherent strain (local-global) method is very timeefficient compared with the others, but it needs plastic strains as input.

- For the T-type fillet weld, the inherent strain (local-global) method is able to estimate the difference of angular distortion caused by change of weld position as predicted in the thermo-elastic-plastic method. No obvious difference in angular distortion under different weld directions is observed in the inherent strain (local-global) method; however, the thermo-elastic-plastic method captures the differences.

- The transverse residual stresses of the T-type fillet weld on the side of first weld pass are lower than those on the other side according to numerical estimation using the thermoelastic-plastic method. Such differences in transverse residual stresses is not observed in the inherent strain (localglobal) method

- For the inherent strain (local-global) method, the influence of block length on estimated angular distortion is significant. Reducing the block length results in an increased angular distortion and reduced level of underestimation.

- Block period is introduced to consider the influence of welding speed together with block length on the estimation of angular distortion in the inherent strain (localglobal) method. It is observed that the level of underestimation can be reduced with the decrease of block period. Consequently, it is suggested the weld bead with a large block period be divided into a number of blocks with an appropriate block period for each.

Acknowledgments Volvo Construction Equipment is thanked for their help in making macrographs on butt welded specimens. SSAB is acknowledged for providing JMat Pro® and their product information.

Funding information This work is supported financially by the Swedish Research Agency Vinnova within the project DIGFOG (smart digitized joining processes) (grant number 2016-04475).

Open Access This article is distributed under the terms of the Creative Commons Attribution 4.0 International License (http:// creativecommons.org/licenses/by/4.0/), which permits unrestricted use, distribution, and reproduction in any medium, provided you give appropriate credit to the original author(s) and the source, provide a link to the Creative Commons license, and indicate if changes were made.

\section{References}

1. Claes O (2017) Design handbook for welded steel products. Techstrat, p 53

2. Andersson O, Semere D, Melander A, Arvidsson M, Lindberg B (2016) Digitalization of process planning of spot welding in bodyin-white. Procedia CIRP 50:618-623
3. Long H, Gery D, Carlier A, Maropoulos PG (2009) Prediction of welding distortion in butt joint of thin plates. Mater Des 30(10): 4126-4135

4. Teng TL, Fung CP, Chang PH, Yang WC (2001) Analysis of residual stresses and distortions in T-joint fillet welds. Int J Press Vessel Pip 78(8):523-538

5. Schenk T, Richardson IM, Kraska M, Ohnimus S (2009) Modeling buckling distortion of DP600 overlap joints due to gas metal arc welding and the influence of the mesh density. Comput Mater Sci 46(4):977-986

6. Bhatti AA, Barsoum Z (2012) Development of efficient threedimensional welding simulation approach for residual stress estimation in different welded joints. J Strain Anal Eng Des 47(8):539552

7. Bhatti AA, Barsoum Z, Khurshid M (2014) Development of a finite element simulation framework for the prediction of residual stresses in large welded structures. Comput Struct 133:1-11

8. Guirao J, Rodríguez E, Bayón A, Jones L (2009) Use of a new methodology for prediction of weld distortion and residual stresses using FE simulation applied to ITER vacuum vessel manufacture. Fusion Eng Des 84(12):2187-2196

9. Ueda Y, Fukuda K, Nakacho K, Endo S (1975) A new measuring method of residual stresses with the aid of finite element method and reliability of estimated values. J Soc Naval Architects Jpn 1975(138):499-507

10. Ueda Y, Fukuda K, Measuring FMA (1980) Theory of three dimensional residual stresses in long welded joints. J Jpn Weld Soc 49(12):845-853

11. Ueda Y, KIM YC, YUAN MG (1989) A predicting method of welding residual stress using source of residual stress (report I): characteristics of inherent strain (source of residual stress)(mechanics, strength \& structural design). Trans JWRI 18(1):135-141

12. Ueda Y, Yuan MG (1993) Prediction of residual stresses in butt welded plates using inherent strains. J Eng Mater Technol 115(4): 417-423

13. Hill MR, Nelson DV (1995) The inherent strain method for residual stress determination and its application to a long welded joint. ASME-PUBLICATIONS-PVP. 318:343-352

14. Yuan MG, Ueda Y (1996) Prediction of residual stresses in welded T-and I-joints using inherent strains. J Eng Mater Technol 118(2): 229-234

15. Luo Y, Murakawa H, UEDA Y (1997) Prediction of welding deformation and residual stress by elastic FEM based on inherent strain (report I): mechanism of inherent strain production (mechanics, strength \& structure design). Trans JWRI 26(2):49-57

16. Souloumiac B, Boitout F, Bergheau JM (2002) A new local-global approach for the modelling of welded steel component distortions. Math Model Weld Phenom 6:573-590

17. Deng D, Murakawa H, Liang W (2007) Numerical simulation of welding distortion in large structures. Comput Methods Appl Mech Eng 196(45-48):4613-4627

18. Khurram A, Shehzad KFE (2012) Simulation of welding distortion and residual stresses in butt joint using inherent strain. Int J Appl Phys Math 2(6):405

19. Barsoum Z, Ghanadi M, Balawi S (2015) Managing welding induced distortion-comparison of different computational approaches. Procedia Eng 114:70-77

20. Virfac GSA, Skyline Building, Av. Georges Lemaître 54, 6041 Gosselies, Belgium

21. Tsirkas SA, Papanikos P, Pericleous K, Strusevich N, Boitout F, Bergheau JM (2003) Evaluation of distortions in laser welded shipbuilding parts using local-global finite element approach. Sci Technol Weld Join 8(2):79-88 
22. Duan YG, Vincent Y, Boitout F, Leblond JB, Bergheau JM (2007) Prediction of welding residual distortions of large structures using a local/global approach. J Mech Sci Technol 21(10):1700-1706

23. Bhatti AA, Barsoum Z, Murakawa H, Barsoum I (2015) Influence of thermo-mechanical material properties of different steel grades on welding residual stresses and angular distortion. Mater Des (1980-2015) 65:878-889

24. Ludwik P (1909) Elements der Technologischen Mechanik 32. Verlag Von Julius Springer, Leipzig

25. J MatPro, Sente Software Ltd., 40 Surrey Technology Centre, Surrey Research Park, Guildford GU2 7YG, United Kingdom

26. Barsoum Z, Lundbäck A (2009) Simplified FE welding simulation of fillet welds-3D effects on the formation residual stresses. Eng Fail Anal 16(7):2281-2289

27. Hemmesi K, Farajian M, Boin M (2017) Numerical studies of welding residual stresses in tubular joints and experimental validations by means of $\mathrm{x}$-ray and neutron diffraction analysis. Mater Des 126:339-350

28. Wikander L, Karlsson L, Nasstrom M, Webster P (1994) Finite element simulation and measurement of welding residual stresses. Model Simul Mater Sci Eng 2(4):845-864

29. Radaj D (1992) Heat effects of welding: temperature field, residual stress, distortion. Springer, Berlin Heidelberg, p 115

30. (2012) SSAB Design Handbook, ÖstbergsTryckeri AB, Nyköping, Sweden, p. 6:25

Publisher's note Springer Nature remains neutral with regard to jurisdictional claims in published maps and institutional affiliations. 